\title{
Assessment of Perception/Awareness of Radiological Impacts of Some Artisanal, Active \& Inactive Mines in Zamfara State
}

\author{
Y. M. Ahijjo \\ Usmanu Danfodiyo University, Sokoto P.M.B 2346, Sokoto State, Nigeria
}

\begin{abstract}
Mining of minerals has caused huge environmental contaminations and grave health effects with little or no detailed evident pathways in recent times. The impacts range from unabated contamination through particulate radionuclide inhalation and ingestion, environmental degradation, worn-out of agricultural lands, increased poverty among inhabitant and increased toxic burden on biodiversity, summing up to a huge human health burden. To assess the perception and awareness of the inhabitants around mines being the stake holders in potential contamination and its adverse effect of exposure, observational data were collected through two separately structured questionnaires during identification of sample points between April 2015 and January 2016 across Gummi, Bukkuyum, Anka, Maru, Gusau, Tsafe and Zurmin Local Government Areas in Zamfara State. The target audience were inhabitants around mines and health personnel in a stratified randomly sampled health centers that attends to cases of related ailments as a result of these mines. The result of 217 respondents in the ratio of 87 for health personnel across health centres to 130 for the dweller who participated in this survey is presented in this paper. Based on the Likert scores, about $80 \%$ of the respondents are of the view that mining in their localities could predispose them to numerous radiological impacts of health maladies and environmental contamination. The responses of the health personnel also revealed that there are evidences of numerous ailments ranging from widespread Upper Respiratory Tracts Infections (URTI) which is connected to aerosol transporting particulate radionuclides from left over mines to heavy casualty inform of death. The result also revealed that most of the inhabitant who responded to our correspondents have either undermined the radiological impacts in their neighborhoods or are biased due to their direct or indirect involvement in the menace. It is therefore recommended that further studies should be intensified on the perceptional analysis to help bridge the potential gaps between the experimental findings and the opinion and perceptions of the inhabitants in relation to the potential radiological future dangers.
\end{abstract}

Keywords: environmental contamination, health-burden, mines, radiological impacts

DOI: $10.7176 / \mathrm{JNSR} / 12-16-04$

Publication date:August $31^{\text {st }} 2021$

\section{Introduction}

As a result of mining activities exposing materials of naturally occurring radionuclides origin, mining localities are deemed to face contamination of various degrees, giving rise to radiation exposure of people living or working in these areas or in their vicinities. In North-Western Nigeria there are a number of private companies, smelters and traditional miners called which have been classified as artisanal, active and inactive miner that spread over unidentified locations in Sokoto (Iullemeden) Basin. Some of commercially mined elements includes; Gemstones, Kaolin, Limestone, Gypsum, Phosphate, Iron Ore, Gold, Monazite, Bauxite etc. The bottlenecks on this premise are the large number of artisanal, active and inactive mines that are in existence unregistered and unaccounted for over a long time within the basin. This has recently strengthened the declaration by the Nigerian Minister of Solid Minerals Development, Dr. Kayode Fayemi, "that the states are now free to explore and exploit their mineral resources has been well received in many quarters. But there are legal bottlenecks that have to be removed before this can become a reality" (Osagie et al., 2016). Until 2015, the number (miners) triggered beyond mere accountability (Ugeh, 2012) and mining issues began to emerge since the number of mines is increasing every year with little or no concerns on inhabitant's health and environmental catastrophe. Some studies have highlighted that mining was on the peak as a catalyst of last century's numerous breakthroughs and invention which marks the turning point for renaissance and industrial revolution where abundant raw materials like sand, gravel, rock, talc, asbestos, limestone, lead, gold, diamond etc. were harnessed for aggregates, concretes, roofing slates, cement, ornaments and were relatively enjoyed with high ignorance of exposure to primordial radionuclide of health hazards and contamination to the environment (Bates, 1969; Harben \& Bates, 1984; Bender, 1986 and Ahijjo and Baba-Kutigi, 2015). Recently, a report in Daily Trust article by Kabiru, (2016), was that radiation has been killing villagers in Adamawa State, Nigeria without much notice from proper investigation and out of the radar of mainstream media.

On a global platform, organizations such as IAEA, (2003), DEP, (2006), COMARE, (2011) and NRSB, (2012) have recommended that observational findings in this respect should be through correspondents in order to achieve radiation contamination assessment. Other researchers like Beck and Miller, (1982) and Till and Grogan (2008) have equally complemented their empirical findings with perceptional results from the 
stakeholders in the radiation contaminated communities investigated. Information on radiological profile of mines in developing countries is generally scarce as noted by IAEA recently. For example, data in the IAEA Technical Report Series Number 419 has been based on studies in Europe and North America. The report observed that data from less developed countries is scarce (IAEA, 2003a). But until now a complete overview of sites and contamination levels in North-western Nigeria does not exist. In many cases, available information is limited so that extensive study is required. Thus, the aim of this study was to evaluate the awareness of the public on the health impacts of radiation exposure level. It focused on assessing the level of radiation and environmental impact profiles in the areas investigated through field survey and in-situ measurement.

\section{Materials and Methods}

In this study, the perception/awareness and opinion of the inhabitants on the radiological concerns of environmental and health hazards of mining activities were sampled through questionnaires, interviews to strengthen the in-situ and in-vitro results of radioactivity measurement conducted throughout Sokoto (Iullemeden) Basin (Shamonda and Maduabuchi, 2014). The study is focused in Sokoto Basin (Kebbi, Sokoto and Zamfara States), a subset of the famous Iullemeden Basin in West Africa, but only the result from Zamfara state will be published in this paper.

The Iullemeden basin extends into this parts of Nigeria with about $60,000 \mathrm{~km}^{2}$ which is just $10.7 \%$ of the Iullemeden basin in West Africa, covering an area of about $500,000 \mathrm{~km}^{2}$ and consists of Sedimentary deposits rich in Limestone and other numerous metal of high economic values (Sharu et al., 2013). The major occupation of the rural dwellers in Sokoto basin is farming activity. Until recently, when gold and other precious metals like tantalite and columbite were discovered in a relative commercial quantity in the area (Tsafe et al., 2012a and Ahijjo et al., 2015).

The Basin experiences low rainfall as compere to other parts of the country with mean annual figure below $600 \mathrm{~mm}$ towards the Nigeria-Niger border and takes place mainly within four months of the year (June - Sept.) with high temperatures and very low humidity prevalence in the area that results in high rate of annual potential evapotranspiration $(>1500 \mathrm{~mm})$ and potential anticipation of drought and desertification (Jonathan et al., 2010). Sokoto (Iullemeden) Basin is characterized with rich Phosphate deposition from the incursion of phosphate rich water from the Tethys Sea. The Tethys Sea during the late Paleocene covered parts of Libya, Sudan, Niger Republic, Chad and Mali (Okosun, 1989; Shaw, 2005 and Merriam-Webster, 2011). The Sokoto phosphate belongs to the Tethyan Phosphogenic Province. The Phosphate was precipitated from sea water during the deposition of the Dange and Gamba Formations. The presence of the oolites indicates the occurrence of acretionary growth phases during the phosphate sedimentation. The calcite found in the phosphate was precipitated from sea water as microsporite. Some of the phosphate was also formed through the process of diagenesis as a partial replacement of carbonate mud by apatite (Akande et al., 1988; Akande et al., 1999 and Johnson et al., 2000). During the regression of the Tethys Sea due to sea level changes, the microsporite was broken up by biological and physiochemical processes. This would have occurred when in a semi-lithified state to be subsequently transported ultrabasinnaly. The bioturbations on the nodules indicates phosphate deposition in shallow water probably within the upper shore face environment. The lack of structural traps from tectonism via differential displacement of faulted blocks hindered economic phosphate accumulations (Kogbe, 1972; Kogbe, 1982; Okosun, 1989 and Danbatta, 2008).

\subsection{Public Awareness and Perception}

Structured questionnaires were used to gather data about the public awareness and perception of radiation exposure due to mining activities of the study area. The questionnaires addressed awareness, observation and evidence data to strengthen the subsequent study on the in-situ and in-vitro measurement of radioactivity. The target audience of the questionnaires were local inhabitants (see Appendix II) and the health personnel from the sampled localities (see Appendix II). The data collected were analyzed quantitatively by Likert scoring method. This was to facilitate input from the real-world conditions, diverse populations and empirical results (Likert, 1932; ICRP, 1991 and Yablokov, 2013). Awareness assessment was carried out with a Likert scale, such as Yes or No; Agree $=[$ ], Strongly Agree = [ ], Disagree = [ ] and Strongly Disagree $=$ [ ]

For objectivity, correspondents were employed to administer the questionnaires based on their fair knowledge of the subject matter and their communication skill to the target audience and to also avoid skepticism of the respondents (EU, 2001). During the sampling and identification of locations, GPS measurement was conducted so as to serve as a frame of reference to the data and the results 1998).

\subsection{Testing the Validity and Reliability of the Questionnaires}

The validity and reliability of the questionnaire was established using a panel of experts and a field test according to Esposito, (2002) and Radhakrishna, (2007) methods based on the EU, (2001) recommendation for radiation protection, evaluation and assessment which involves questionnaire. 


\section{Sampling and Distribution of Respondents}

The process of stratifying the members of the population into homogeneous subgroups before carrying out the sampling was used to stratify the states into Kebbi, Sokoto and Zamfara States respectively. The local government areas distribution in table 1 were based on cluster sampling methods according to Bennet et al. (1991). The sample points were based on accessibility issues arising in most locations of Zamfara State which includes Cow rustling, Kidnappers, Arm banditries and communal clashes between Fulani-herdsmen and Villagers. The questionnaires were administered to the respondents through a stratified random sampling by proportion with the expression in equation 1.

$$
\Sigma_{\sigma}=\frac{S_{\rho}}{\sigma}\left(N_{k}\right)
$$

Where $\Sigma_{\sigma}$ is the sum of the questionnaires distributed, $S_{\rho}$ is the number of sample points, $\sigma$ is the sum of the sample points and $N_{k}$ sum of Questionnaires.

The strata were ensured to be mutually exclusive and collectively exhaustive; no member of the population was excluded before randomizing (Singh and Audu, 2013). This was done to improve the representativeness of the sample by reducing sampling error and biasness. The number of sample points for the radiation measurement was used as a guide for the number of questionnaires allocated to any local government area in each state. This is responsible for the variation of the number of questionnaires presented in the result shown in table 1.

Table 1: Distribution of the Respondents in Zamfara State

\begin{tabular}{llllccc}
\hline S/N & LGA & S/Points & \multicolumn{4}{c}{ Number of Questionnaires } \\
\cline { 3 - 6 } & & & $\begin{array}{c}\text { Distributed to } \\
\text { Inhabitants }\end{array}$ & $\begin{array}{c}\text { Responded by } \\
\text { Distributed to } \\
\text { Health Personnel }\end{array}$ \\
\hline 1. & Gummi & 10 & 38 & 38 & 22 & 20 \\
2. & Bukkuyum & 10 & 38 & 34 & 22 & 20 \\
3. & Anka & 6 & 23 & 12 & 14 & 10 \\
4. & Maru & 8 & 30 & 20 & 18 & 7 \\
5. & Gusau & 3 & 12 & 12 & 7 & 7 \\
6. & Tsafe & 3 & 12 & 12 & 7 & 5 \\
7. & Zurmi & 2 & 7 & 7 & 5 & 84 \\
\hline
\end{tabular}

Due to the proximity of most respondents to the mines and the proportions, 160 questionnaires were distributed to the inhabitants and 95 for health personnel in the ratio calculated in table 1. 38 questionnaires were administered to Gummi and Bukkuyum respectively based on stratified random sampling by proportion of mines, 30 for Maru LGA, 23 for Anka, 12 for Gusau/K. Koshi and Tsafe and 8 for Zurmi LGA respectively for inhabitant's responses. On the other hand, 22 questionnaires were administered to Gummi and Bukkuyum, 18 to Maru, 14 for Anka, and 7 each for Gusau/K. Koshi, and Tsafe and 5 for Zurmi LGA respectively for the health personnel responses. A total of 219 questionnaires were responded to out of 255 administered.

\section{Results and Discussion}

Based on the result of this survey, figure 1 presents the background of the respondents in form of demographic data. The percentage of the respondents from urban and rural settings were $17 \%$ and $72 \%$ respectively where about $10 \%$ of the distributed questionnaires were returned without response. Empirically, this finding shows that most of the mining activities are concentrated in the villages as compared to the cities. The percentages of male to female respondents were $68 \%$ and $32 \%$, respectively, which shows more male participation than female due to the nature of mining being more mannish according to our correspondents. On their account of age distribution of the people that are mostly engaged in mining, the result shows that about $65 \%$ of the miners are in their prime age of $19-39$ years in contrast to $24 \%$ and $11 \%$ for the older ones that responded to this survey. 


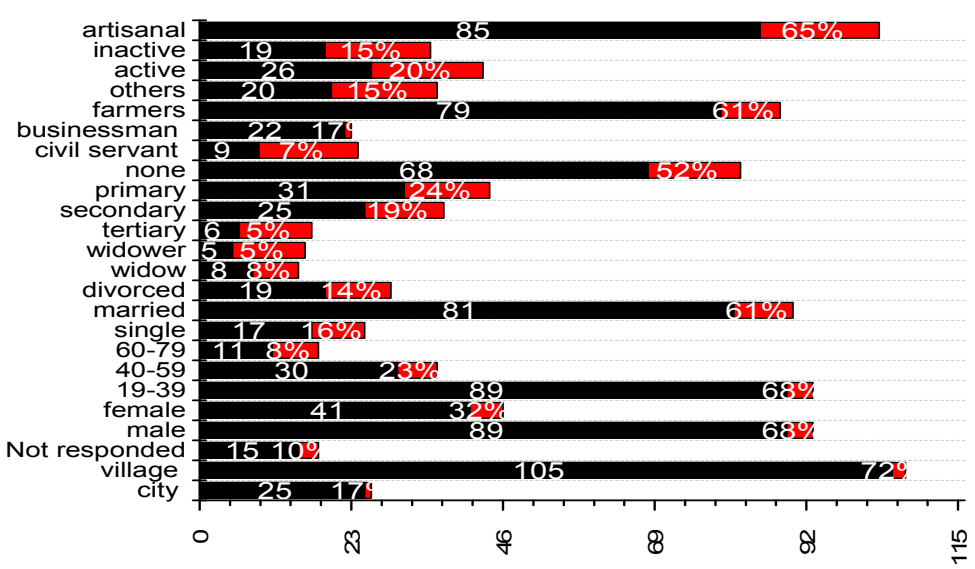

Figure 1: A Stack bar Chart of the inhabitant's demographic distribution

The data of their marital status shows that $61 \%$ are married and the rest $15 \%, 12 \%, 7 \%$, and $5 \%$ were single, divorced, widows, and widowers, respectively. The percentage of their literacy were $4 \%, 19 \%, 26 \%$ and $51 \%$ for tertiary, secondary, primary and those who are not formally educated, respectively. Occupationally, most of the inhabitants who responded are mostly farmers at about $57 \%$ in contrast to Civil servants, Businessmen and Others who made up $8 \%, 18 \%$ and $17 \%$, respectively on the Likert scale. This was due to the local influences of tradition of the inhabitants and their overwhelming indulgence in subsistence farming. The prominent mining activities was identified as artisanal type of mining which rates $64 \%$ against active and inactive mining that were merely $22 \%$ and $14 \%$, respectively.

\subsection{Awareness and Perception of the Inhabitants on Environmental/Health Impacts}

The result of the responses from the inhabitants around the mines in Zamfara State is presented in Figure 2. Their awareness was scored $55 \%$ no and $45 \%$ yes. This means that the dangers of environmental and health impacts of artisanal, active and inactive mining in these localities will continue unabated due to low level awareness of the potential radiological impacts which might be responsible by their direct or indirect participation in the mining activities.

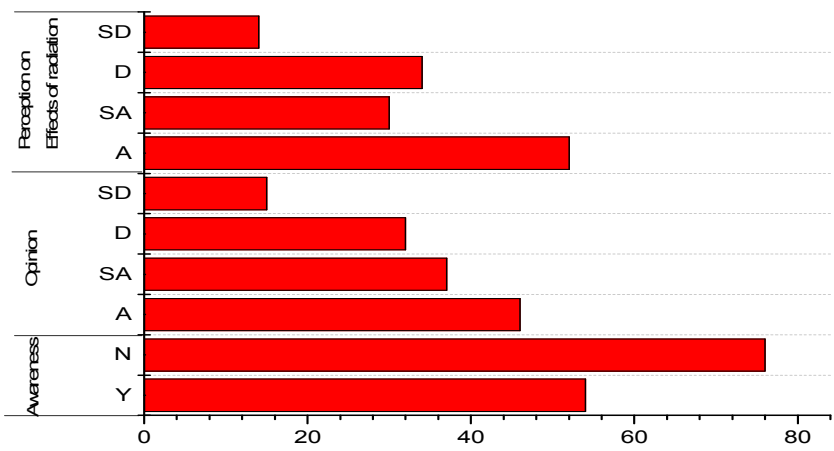

Figure 2: A Bar Chart of the Inhabitants Response to the Survey on Radiation Exposure from Environmental Impacts of Mining

The percentage of the respondent's opinions based on agree, strongly agree, disagree and strongly disagree was scored $33 \%, 28 \%, 27 \%$ and $12 \%$, respectively shows a mixed perceptions which implies that potential impact of the mining is dreadful but never the less ignored due to the immediate financial benefits that could be derived. Their responses on the effects of radiation which could emanate from some environmental factors if not properly handled, was also significant in agreeing and strongly agreeing to the potential effects at about $39 \%$ and $23 \%$ while they disagree and strongly disagree at $22 \%$ and $12 \%$ on their perceptions. This is also a reflection of agreement between the respondent's perceptions and their demographic accounts. 


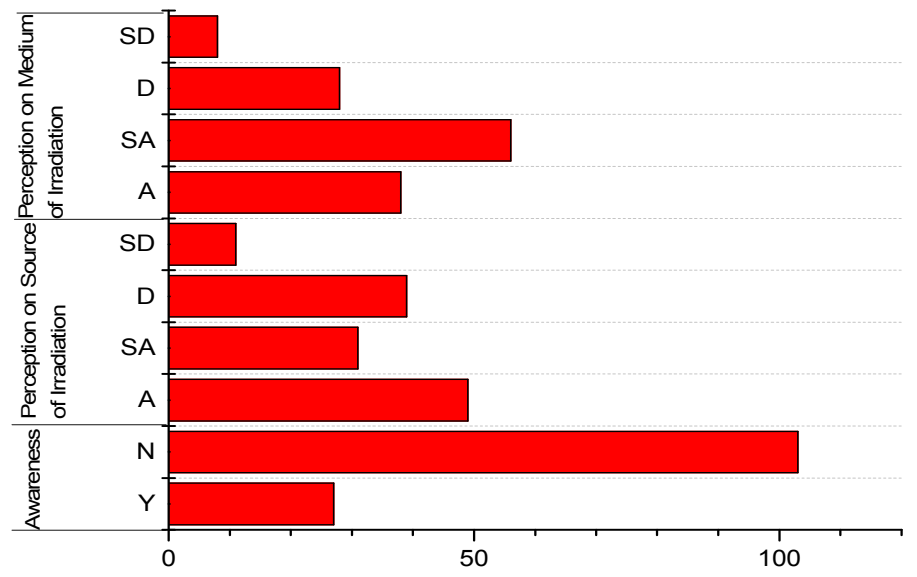

Figure 3: A Stack Bar plot of the Inhabitants Response to Survey on Mining activities as a Means of Irradiation Source from the Environment

External irradiations by commonly known Alpha, Beta and Gamma rays are of little or no much concerns than internal irradiations which could be due to ingestion or inhalation of particulate radionuclides in the contaminated air, food and water which could pose grave dangers to biological systems (Baba-Kutigi et al., 2010 and Ahijjo et al., 2014). On this premise, the questionnaire was structured to gather perceptions of the potential irradiation pathways to the inhabitants. Figure 4 is a chart of the result of the survey of the inhabitants perceptions based on the Likert method of scoring. The percentage of the inhabitant's awareness was about $33 \%$ and $67 \%$ for those who affirmed and those who declined on what irradiation could be all about. The percentage of perception for the irradiation pathways was also captured (seen Appendix I) in the survey, this was found in a significantly agree and strongly agree at about $37 \%$ and $26 \%$ in contrast to disagree at $28 \%$ and strongly disagree at $9 \%$, respectively. The percentage of responses to potential medium of irradiation are $31 \%, 39 \%, 18 \%$ and $12 \%$ on the bases of agree, strongly agree, disagree and strongly disagree, respectively. This means that the inhabitants need an in-depth awareness and enlightenment on this caption due to the significant low awareness.

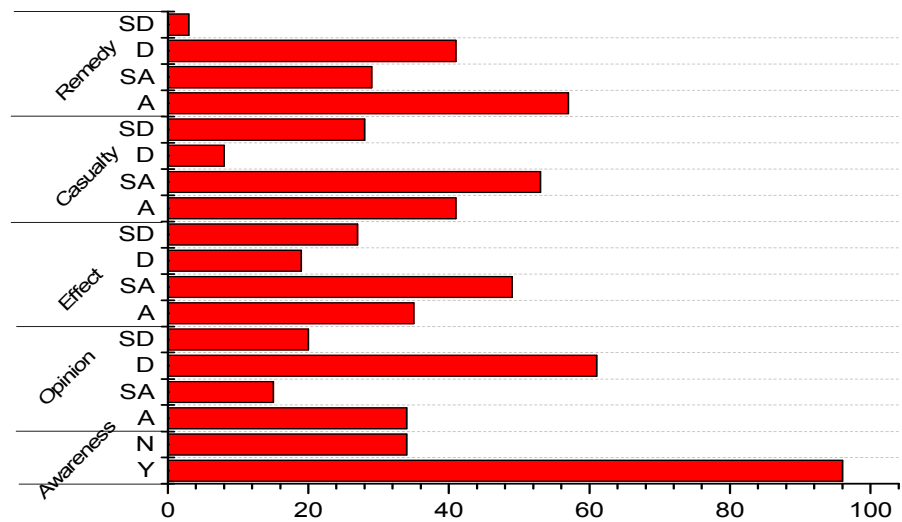

Figure 4 (a - d): Bar charts of the results of inhabitant's perception on radiological impacts of mining

Figure $5(\mathrm{a}-\mathrm{d})$ is the result of the inhabitant's perception due to ionizing radiation based on their interactions with the correspondents. This is to ascertain the inhabitant's awareness on the subject matter, they were scored based on Likert scale. Their awareness was significantly high at about $74 \%$ against $26 \%$. This was viewed to pave way for further productive survey on the other items in the questionnaire. In the same vein, their opinions was surveyed by scoring $26 \%, 12 \%, 47 \%$ and $15 \%$ for those who responded to agree, strongly agree, disagree and strongly disagree on the mines as the medium that could lead to irradiation by either inhalations or ingestion. The relative low responses in this result were due to the inhabitant's involvement in the mining activities according to our correspondents. 


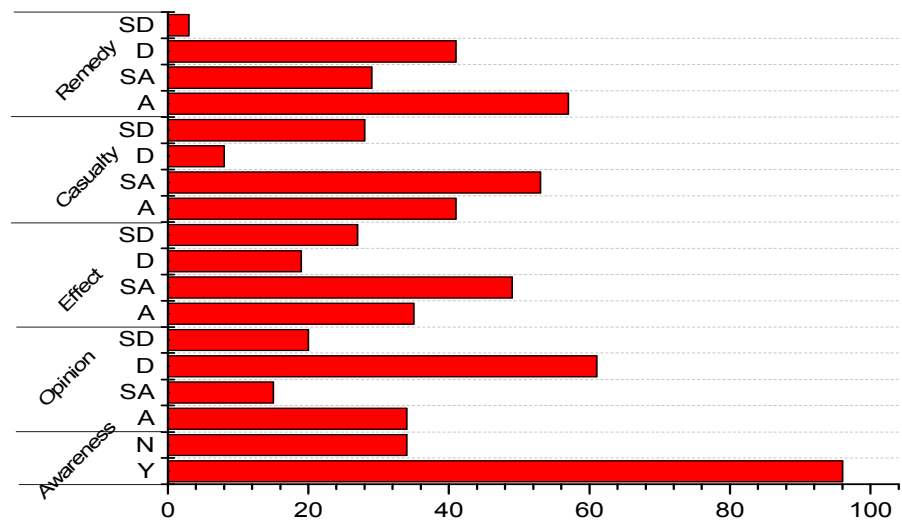

Figure $5(\mathrm{a}-\mathrm{d})$ : Bar charts of the results of inhabitant's perception on radiological impacts of mining

On the potential effects of ionizing radiations, their percentages were $27 \%, 38 \%, 15 \%$ and $20 \%$ for those who agree, strongly agree, disagree and strongly disagree respectively. Which means that most of them are of the perceptions that exposure to ionizing radiation is a potential risk that could result to a grave radiological impact. Based on their perceived or active awareness on the level of casualties, the percentage scores were $32 \%, 41 \%$, $5 \%$ and $22 \%$ for agree, strongly agree, disagree and strongly disagree respectively on the Likert scale. This means that the respondents have a significant perception on the casualty that could result from the impacts of ionizing radiation due to mining activities in their localities.

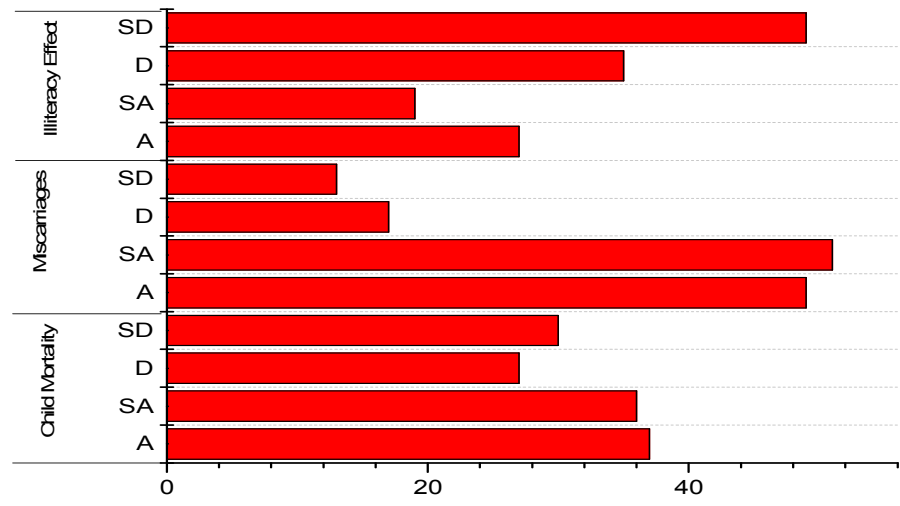

Figure $6(\mathrm{a}-\mathrm{d})$ : Bar charts of the results of inhabitant's perception on radiological impacts of mining

For the possible remedies, their perceptions were scored $44 \%, 22 \%, 32 \%$ and $2 \%$ on the bases of agree, strongly agree, disagree and strongly disagree respectively. This is to say that the present approach could create awareness, medium of communication and subsequent remedies to the dangers. To verify deeper, general mortality rate was observed and scored $27 \%, 48 \%, 15 \%$ and $10 \%$ for agree, strongly agree, disagree and strongly disagree respectively. Which indicates a significant mortality rates from the responses of the inhabitants in these localities. Male mortality was scored $24 \%, 43 \%, 15 \%$ and $18 \%$ for agree, strongly agree, disagree and strongly disagree on the Likert scale. The significant rate of the male mortality was directly or indirectly linked to their indulgence in mining and farming according to our correspondents. Based on the Likert scale, the percentage of the respondent's perception on female mortality rate are $46 \%, 29 \%, 17 \%$ and $8 \%$ for agree, strongly agree, disagree and strongly disagree. This shows that their perception is significantly high in contract to the male mortality which could be due to female radiosensitivity over male according to a study reported by Wallace et al., (2003). 


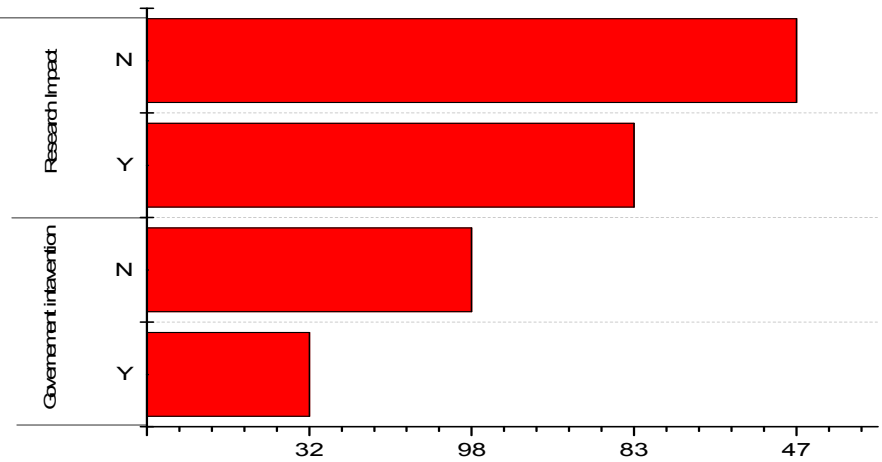

Figure 7 (a - d): Bar charts of the results of inhabitant's perception on radiological impacts of mining

On the bases of adult mortality their responses were scored $28 \%, 33 \%, 22 \%$ and $17 \%$ for agree, strongly agree, disagree, and strongly disagree on the Likert scale. This shows that the adult mortality rate is significantly high which was said to be contributed by factors like exposure to the impact of mining and poor health care in most remote settlement. On the child mortality rate, their responses were scored $28 \%, 28 \% 21 \%$ and $23 \%$ for agree, strongly agree, disagree and strongly disagree. This could also signal a negative radiosensitivity tendencies of the children in contrast to adults. Miscarriages in pregnant women is often linked to radiation exposure by most Oncologists that it leads to fetal death (Pamela and Stacy, 2010 and Abdallah and Elshikh, $2015)$, the survey on this concern revealed that about $38 \%, 39 \%, 13 \%$ and $10 \%$ respondents agree, strongly agree, disagree and strongly disagree on the Likert scale. This means that there is a significant level of miscarriages due to health impact of ionizing radiation level in these localities.

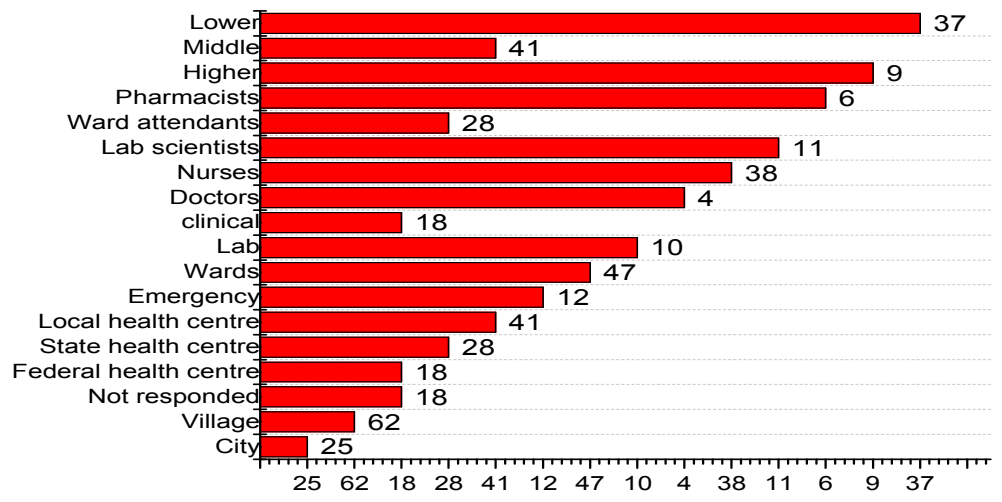

Figure 8: A Bar Chart Illustrating the Demography of the Participants of the survey

During the survey, the level of illiteracy was also included so as to observe the relationship if improved literacy level may serve a positive effect in the finding. This was scored $22 \%, 16 \%, 28 \%$ and $34 \%$ on the Likert scale for those who agree, strongly agree, disagree and strongly disagree respectively. This shows that the respondent is of the views that some impacts could be fairly connected to illiteracy level in the localities. Government intervention was scored $25 \%$ yes and $75 \%$ no which indicates that there is insignificant level of government intervention. This could be blamed on the widespread artisanal mining activities in the localities. In order to ascertain that the research could improve the underlying questions, the inhabitants were scored $64 \%$ yes and $36 \%$ no for their responses on research impacts. This shows that the interactions between our correspondents and the respondents whose majority are stakeholder directly or indirectly in the mining activities through questionnaires will save the environment or lives of the inhabitants.

Figure 8 is the result of the demographic data of the respondents from the sampled health centres in Zamfara state. Based on the Likert scales, the percentage of the respondents from health centres in the cities and villages were $24 \%$ and $59 \%$ respectively with $17 \%$ of the questionnaires not responded. This means that there are more health centres in the villages that participated in this survey than in the cities. The sampled health centres where categorized base on federal, state and local health centres which appeared $21 \%, 32 \%$ and $47 \%$ in terms of the respondents that participated in the survey. 

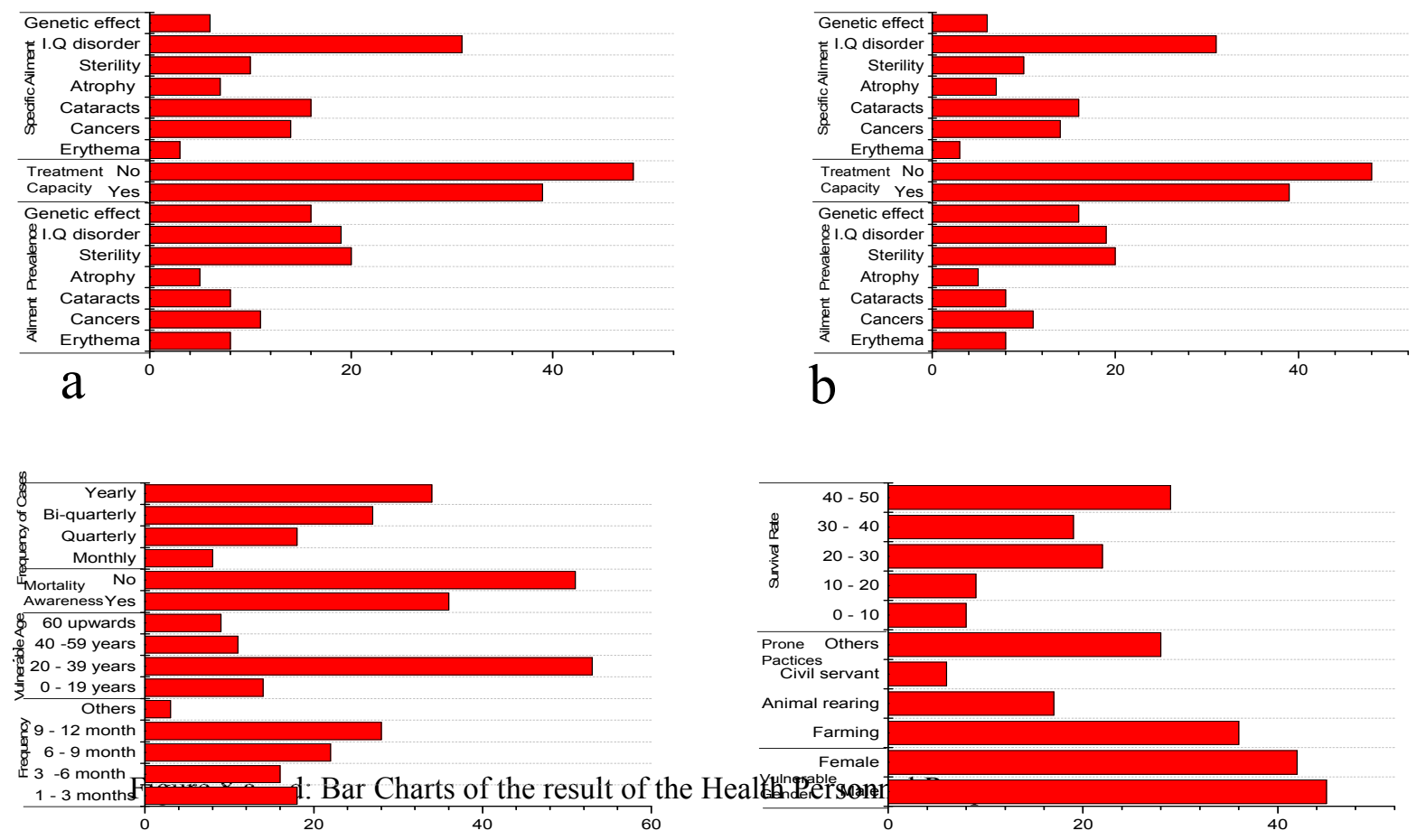

$\mathrm{C}$

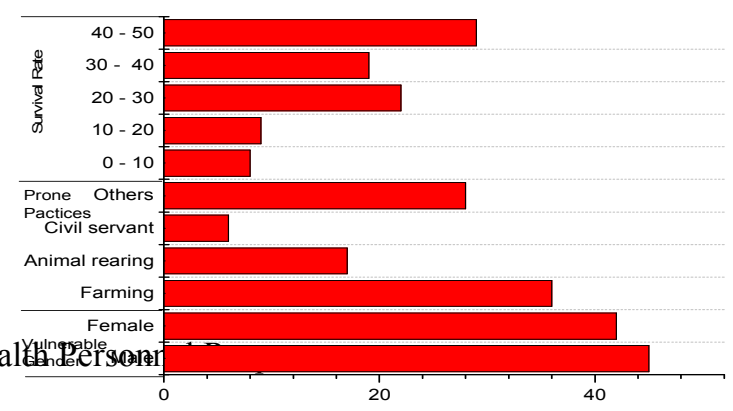

d

This means that there are more respondents in the state and local health centres in participation. The respondent from the units were also scored $14 \%, 54 \%, 11 \%$ and $21 \%$ on the bases of emergency unit, wards, labs and clinical. This shows that more respondents from the wards participated than other respondents from other units. This could be due to their relatively high numbers in presence in their centres than other personnel in other units. To identify the respondent's personality, their distribution was based on Doctors, Nurses, Lab Scientists, Ward Attendants, and Pharmacists which were scored 5\%, 44\%, 13\%, 32\% and 6\% respectively on the Likert scale. This is in fair agreement with the scores of the distributions based on units which shows more respondents in the wards than other units.

Based on their social status, in the order of higher, middle and lower status, it appears $10 \%, 47 \%$ and $43 \%$ respectively. This means that only few of the respondents in the sampled health centers are lower rank officers in contrast to the other respondents.

Figure 8 is the result of the responses of the health personnel from sampled health centers in Zamfara State. Based on Likert scale, the ailment prevalence was scored, $9 \%, 13 \%, 9 \%, 6 \%, 23 \%, 22 \%$ and $18 \%$ for erythema, cancer, cataracts, atrophy, sterility, learning disability and genetic effects. It means that the health personnel's perception on the ailment prevalence in these localities is significant for sterility, learning disability, genetic effects and cancers. 


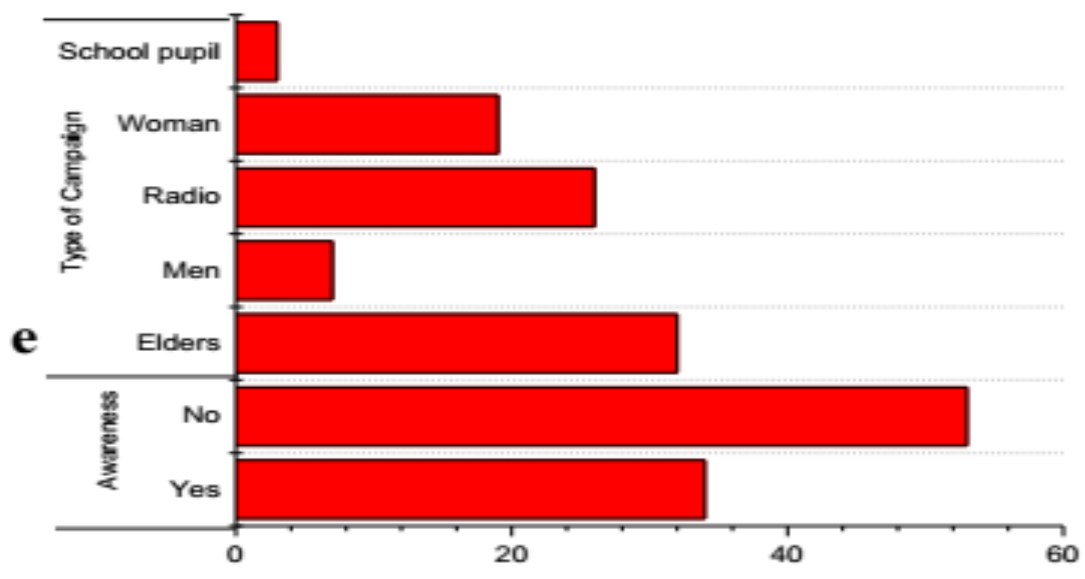

Figure 9: Bar Charts of the result of the Health Personnel Responses

For the treatment capacity, their responses were $45 \%$ yes and $55 \%$ no which means that there is low treatment capacity in most health centres in these localities. The more specific ailments were identified as learning disabilities $36 \%$, cataracts $18 \%$, cancer $16 \%$ and sterility $11 \%$ in contrast to less specific ailments which were erythema $3 \%$, genetic effects $7 \%$ and atrophy $8 \%$. The frequency of the ailments reported was between 9 12 month at about $32 \%$ and $6-9$ months at about $25 \%$ in contrast to $21 \%, 18 \%$ and $3 \%$ for $1-3$ months, $3-6$ months and others that were not specified by the respondents. The most vulnerable ages between $0-9$ years, 2039 years, $40-59$ years and 60 upwards were $16 \%, 61 \%, 13 \%$ and 10\%. Which shows that the most vulnerable age range is within the prime age. Their responses to mortality awareness was $41 \%$ yes and $59 \%$ no which correlates fairly with the inhabitants responses on mortality awareness.

For the frequency of mortality cases, the responses were $90 \%, 21 \%, 31 \%$ and $39 \%$ for monthly, quarterly, Bi-quarterly and yearly reports. The most vulnerable gender was $52 \%$ male against $48 \%$ female from the responses. Which could be due to the male's active involvement in the practices that predisposes them to radiation exposure than female. On their perceptions of possible prone practices, it was $41 \%$ farming, $20 \%$ animal rearing, $7 \%$ government jobs and 32\% for other that was left unspecified. The ailment survival rates between 0-10years, 10-20 years, 20-30 years and 40-50 years were scored 9\%, 10\%, 25\%, 22\% and 33\% respectively. Which falls close to the average life expectancy of Nigerians of about 51 years according to National Population and Housing Census, (2006) and WHO, (2014). Possible enlightenment campaign was scored, where $39 \%$ responded yes and $61 \%$ responded no for awareness campaign. Based on the type of campaign, their responses were $37 \%, 8 \%, 30 \%, 22 \%$ and $3 \%$ for elderly people, men, women, school pupil and radio stations respectively. This shows that means of awareness is rendered negligible and could compound dangers to the inhabitants.

\subsection{Perceptional Result of Environmental Impacts}

The prevalence of artisanal mines gathered from the responses is significantly $65 \%$ from this survey. The inhabitant's perceptions on environmental impacts ranges from land degradation, dramatic loss of farm land, domestic water contamination, air pollution of various dimensions and unregulated cutting down of trees. The severity of impact, however, varies depending on whether the mine is active or inactive. The implications of this result is a buttress point in perfect agreement with the recent report by WHO, (2016), that over $90 \%$ of the world inhabitant especially those in the rural areas are breathing contaminated air which is responsible for more than 6 million deaths a year.

From the questionnaire responses, it shows that about $79 \%$ of the inhabitants sampled agreed that activities of mining generally are implicating to their natural environment. This indeed have revealed that most mining localities have been facing domestic water contamination including rivers, streams, wells and seasonal ponds which are the major sources of domestic water. A further assessment indicates that the radiological impacts could also emanate from the piles of waste, abandoned excavated land from these mines. Excavated pits are left unfilled which could serve as sources of generating contaminated particulate radionuclides in the environment through aerosols that could hardly be settled by the force of gravity. Such factors become potential dangers to all living systems in the environment. Hence, the objectives of the study which sought to assess the radiological impacts of mining in Sokoto Basin through soil, water and vegetation from these mines is therefore justified. 


\subsection{Perceptional Result of Health Impacts}

Undisputable health effects of mining activities are remarkable from the environmental assessment discussed above. The research revealed that high prevalence of ailments ranging from Upper Respiratory Tracks Infections caused by inhaled dust, skin infections, Genetic disorder, Erythema and death among residents could be the direct or indirect effects of the radiological burden due to mining activities in Sokoto Basin. Questions of different structures were asked to confirm or decline the claim that people feel their health condition related to the artisanal, active and inactive mines in their respective communities is in grave dangers, about $80 \%$ affirmed while $20 \%$ declined. The results further establishes that about $80 \%$ of the sampled inhabitants perceived that the high prevalence of some ailments is strongly correlated with these activities. It is also good to note as a recap that the radiological health impacts of mining activities ramify the Likert scores on relatively low participations of the health personnel in federal and state health centers which leaves high dependency on traditional health providers, self-medication which could leads to drug abuse as coping strategies because of scarcity of health facilities in most remote mining locations and crude application of herbs. It was also noted that the ailments identified by the respondents formed part of the top ten radiological cases reported at the various health centers within the reports of our surveys from April 2015 - January 2016. Despite the significant occurrence in a relatively glaring mortality rates in all spheres of age groups reported in the responses of the participants of these findings, most of the ailments enlisted still constitutes causes of deaths related to mining activities in the Sokoto Basin which call for further and in-depth research.

\section{Conclusion}

The major findings in this study is a clear evident of environmental and health impacts due to artisanal, active and inactive mining in the stratified sampled points. This result is directly a function of the sources of exposure to some radiation from the mines which will be further buttressed by the result of the in-vitro analysis from soil, water and vegetation. Most inhabitants who have responded to our survey lacks the basic awareness and knowledge of the after mat of exploration and mining activities around their homes and living places, a key observation in the survey. So this could be further complemented with the next result from the in-vitro measurement. Several health and environmental issues related to the mining activities have been unveiled due to relative level of illiteracy and means of livelihood that mining served to the inhabitants. Most of these areas suffered from environmental contaminations due to activities which predisposes the inhabitants to radiological health impacts and environmental risks as shown in the response by the inhabitants. Lastly, the spectrum of sample points as well as the measured GPS locations in this study could serve as a source of reference for further analysis and reviews.

\section{Acknowledgement}

This research is the preliminary stage of a PhD study, funded and supported by TETfund under the Management of Usmanu Danfodiyo University, Sokoto. A warm acknowledgement is due to the following persons; Mallam A. A Musa Chief Academic Technologist, (Coordinator Physics Laboratories), Usmanu Danfodiyo University Sokoto. The Royal Fathers of Bukkuyyum, Yargalma, Bulunkutu, Gummi, Falale, to mention but few. Physics Department, Federal University Dutsinma, Katsina State, Nigeria

\section{References}

Abdallah, I. and Elshikh, M. (2015). Effect of radiation on pregnancy. International Journal of Medicine and Medical Sciences. 7 (5): pp. $98-101$.

Ahijjo Y. M., Baba-kutigi A. N., Momoh M. and Moreh A. U. (2015) A Review of Sequential Extraction Method for Lead in Samples: A Case Study of Artisanal Mines of Sokoto Basin (Zamfara State). IJSRST, 1 pp. 2395-602.

Ahijjo, Y. M. and Baba-Kutigi, A. N. (2015). A Model Of Analytical Theory For Indoor Radon Contemination In Sokoto Metropolis. Journal of Multidisciplinary Engineering Science and Technology (JMEST), 2 pp. 2460 - 2463.

Ahijjo, Y. M., Baba-Kutigi, A. N. and Momoh, M. (2014). Assessment of Indoor Cancer Linked Radionuclides in Sokoto Urban Dwelling. Journal of Natural Sciences Research. ISSN 2224-3186(Paper) 4, No.1.

Akande, S. O., Abimbola, A. F. and Erdtmann, B. D., (1999). Cretaceous Tertiary Phosphorites in Nigeria: Paleoenvironments and Genesis. In Stanley et al., (eds). Mineral Deposits, Balkema, Rotterdam, 5 pp. 10691072.

Akande, S. O., Fakorede, O. and Muckey, A. (1988). Geology and genesis of gold bearing quartz veins at Birni Yauri and Okolom in the Pan-African domain of western Nigeria. Geologie en Mijnbouw 67. Pp 41-51.

Arai, T., Aiyama, Y., Sugi, M. \& Ota, J. (2001), "Holonic Assembly System with Plug and Produce”, Computers in Industry 46, Elsevier, 289-299.

Baba-Kutigi, A. N., Dim, L. A., Odunze, A. C. and Umar, I. M. (2010). "Soil Water Balance Approach in the 
Root Zone of Maize (95 TZEE-Y) Using Capacitance Probe (Diviner 2000) in Northern Guinea Savannah of Nigeria," Bayero Journal of Pure and Applied Sciences, 3 pp. 87-90.

Bates R. L. (1969): Geology of the industrial minerals and rocks, 2nd edition (translated into Russian). Dover Publications Inc., New York, pp. 459.

Beck, H. L., \& Miller, K. M. (1982). Temporal Variations of the Natural Radiation Field. Transactions of the Second Special Symposium on the Natural Radiation Environment, Wiley Eastern. Glove Publishers Inc., Pennsylvania, pp. 201

Bender F. (1986): Angewandte Geowissenschaften. Band IV Ferd. Enke Verlag, Stuttgart, pp. 161-267

Bennet, S., Woods, T., Liyanage, W. M. \& Smith, D. L. (1991). A simplified general method for cluster sample surveys of health in developing countries. World Health Statistics Quarterly, 44 (3), 89 - 106.

COMARE, (Committee on Medical Aspects of Radiation in the Environment) (2011). Fourteenth report: Further consideration of the incidence of childhood leukemia around nuclear power plants in Great Britain, Health Protection Agency, may 2011.

Danbatta, U.A. (2008). Precambrian crustal development in the northwestern part of Zuru schist belt, northwestern Nigeria. Journal of Mining and Geology. 44 (1), pages 45-56.

DEP (Connecticut Department of Environmental Protection) (2006). Reassessment of Millstone Power Station's Environmental Monitoring Data. Division of Radiation (March). (Unpublished).

EC, (2001). Radiological considerations with regard to the remediation of areas affected by lasting radiation exposure as a result of a past or old practice or work activity. European Commission Document on Radiation protection 124. Pp. 8.

Erskine, W.D. \& Green, D. (2000). Geomorphic effects of extractive industries and their implications for river management: the case of the Hawkesbury-Nepean River, New South Document, pp. 94-102.

Esposito, J. L. (2002). Interactive, multiple-method questionnaire evaluation research: A case study. Paper presented at the International Conference in Questionnaire Development, Evaluation, and Testing (QDET) Methods. Charleston, SC.

IAEA (International Atomic Energy Agency) (2003). Testing of Environmental Transfer Models using Data from the Atmospheric Release of Iodine-131 from the Hanford Site, USA, in 1963. Report of the Dose Reconstruction Working Group.

IAEA, (2003). Extent of Environmental Contamination by Naturally Occurring Radioactive Material (NORM), IAEA Technical Report Series No. 419, Vienna-Austria.

IAEA, (2006). European Atomic Energy Community, Food and Agriculture Organization of the United Nations, International Atomic Energy Agency, International Labour Organization, International Maritime Organization, OECD Nuclear Energy Agency, Pan American Health Organization, United Nations Environment Programme, World Health Organization, Fundamental Safety Principles, IAEA Safety Standards Series No. SF-1, IAEA, Vienna.

ICRP, (1991). Recommendations of the International Commission on Radiological Protection. ICRP Publication 60. 1st ed. Amsterdam: Elsevier; 1991 Apr 12. Part 1, part 2; 191 p., 207 p.

Johnson, A. K., Pierre, R., \& Lang, J. (2000). Le basin sedimentairea phosphates du Togo (MaastrichtianEocene): Stratigraphae, environnements et evolution. Jour. Afri. Earth Sci., 30(1), 183200.http://dx.doi.org/10.1016/S0899-5362 01, pp. 15-4.

Kabiru, R. A. Y. (2016). Uranium Contamination: 'Radiation has been killing Adamawa villagers for years' Babies born deformed in Michika areas. Daily Trust Newspaper, Special Report. Saturday, July 30. Pp. 10 -11 .

Kogbe, C. A. (1982). Geology of the Southeastern (Sokoto) Sector of the Iullumineden Basin. Bulletin, 32, pp 420.

Kogbe, C.A. (1972). Geology of the Upper Cretaceous and Lower Tertiary sediments of the Nigerian sector of the Illummeden Basin (West Africa), Geol. Rdsch. 62, $197-211$.

Kolo, M.T., Baba-Kutigi, A. N., Olarinoye, I. O. and Sharifat, I. (2012). Assessment of Natural Radioactivity Levels and Radiation Hazards in the Tertiary Institutions in Minna, Niger State, Nigeria. Continental Journal of Environmental Sciences, 6, 25-31.

Likert, Rensis. "A Technique for the Measurement of Attitudes." Archives of Psychology 140:pp 1 - 55.

Makweba, M. M. and Ndonde, P. B. (1996). The mineral sector and the national environmental policy. In: M.J. Mwandosya et al (Eds.), Proceedings of the workshop on the national environmental policy for Tanzania (Dar es Salaam, Tanzania), 1996. (pp 164-173).

NRSB, (Nuclear and Radiation Studies Board), (2012). Division of Earth and Life Studies. Washington, DC: National Academy Press.

OECD, (2011) Organisation for Economic Co-operation and Development "Dose Constraints in optimization of occupational Radiological protection". OECD/NAE/CRPPH No 1.

Osagie, E., Nwosu, S. and Tunji, B. (2016). States and Exploration of Solid minerals. Daily Sun, Monday, 
Janaury 25, 2016 pp. 17.

Pamela, M. W. and Stacy, F. (2010). Health effects of prenatal radiation exposure Am. Fam. Physician 82(5): $488-493$.

Population and Housing Census, (2006). Priority $\quad$ Table VolumeIV".http://www.population.gov.ng/index.php/publications/141-population-distribution-by-age-andsex-2006-census-priority-tablesvol-4

Radhakrishna, R. B. (2007). Tips for Developing and Testing Questionnaires/Instruments. The Pennsylvania State University University Park, Pennsylvania. February 2007 // Volume 45 // Number 1 // Tools of the Trade//1TOT2.Brr100@psu.edu

Shamonda, J. A. \& Maduabuchi, C. M. (2014). IAEA - Assisted Sahel Project RAF7011: Progress Report on the Iullemeden (Sokoto) Basin in Nigeria. Integrated and Sustainable Management of the Shared Aquifer System and Basins of the Sahel Region, Vienna, Austria, 5 - 8 May 2014. Paper presented at the First Coordination and Governance Meeting on Project RAF70 11: Pp 2 - 6.

Sharu, M. B., Yakubu, M., Noma, S. S., \& Tsafe, A. I. (2013). Characterization and Classification of Soils on an Agricultural landscape in Dingyadi District, Sokoto State , Nigeria, 21(2), 137-147.

Shaw G. (2005). Applying radioecology in a world of multiple contaminants. Journal of Environmental Radioactivity 81. 117-130.

Singh, R. V. K. and Audu, A. (2013). Efficiency of Ratio Estimators in Stratified Random Sampling Using Information on Auxiliary Attribute. International Journal of Engineering Science and Innovative Technology (IJESIT). ISSN: 2319-5967. Volume 2, Issue 1, pp. 166-172

Stochioiu, A.; Bercea, S.; Sahagia, M.; Ivan, C.; Tudor, I. and Celarel, A. (2011). The Measurement of the Natural Radiation Background in a Salt Mine. Environmental Physics. Paper presented at Third IRPA Congress, 14-18 June 2010, Helsinki, Finland. Rom. Journ. Phys., Vol. 56, Nos. 5-6, P. 757-761.

Techawiboonwong, A., Yenradeea, P. \& Das, S. (2006). A Master Scheduling Model with Skilled and Unskilled Temporary Workers", Production Economics 103, Elsevier, 798-809.

Till, J. E., and Grogan, H. A. (2008). Radiological Risk Assessment and Environmental Analysis. New York: Oxford University Press.

Tsafe, A. I., Hassan L. G., Sahabi D. M., Alhassan, Y. and Bala, B. M. (2012a). Assessment of heavy metals and mineral compositions in some solid minerals deposit and water from a gold mining area of Northern Nigeria. International Research Journal of Geology and Mining, 2(11), 254-260.

Tsafe, A. I., Hassan, L. G., Sahabi, D.M., Alhassan, Y. and Bala, B. M., (2012b). Evaluation of Heavy Metals Uptake and Risk Assessment of Vegetables Grown in Yargalma of Northern Nigeria. ISSN 2090-4304 Journal of Basic and Applied Scientific Research, 2(7) pp. 6708-6714,

Ugeh, P. (2012). Revocation of Mining Licenses in Order, THIS DAY LIVE (Oct. 23, 2012), http://www.thisdaylive.com/articles/revocation-of-mining-licences-in-order/128441/ Accessed 02/082016.

UNSCEAR, (2010). Sources and effects of ionizing radiation, annex B: exposure of the public and workers from various sources of radiation. New York: United Nations Scientific Committee on the Effect of AtomicRadiations.

Valckenaers, P., Van Brussel, H., Bongaerts, L. \& Wyns, J. (1997), "Holonic Manufacturing Systems", Integrated Computer Aided Engineering 4 (3), pp 191-201.

Van Brussel, H., Wyns, J., Valckenaers, P., Bongaerts, L. \& Peters, P. (1998), "Reference Architecture for Holonic Manufacturing Systems: PROSA”, Computers in Industry 37(3), pp 255-274.

Wallace, W. H. B, Thomson, A. B. and Kelsey, T.W. (2003). The radio sensitivity of the human oocyte. European society of human reproduction and embryology. Vol. 18, No.1 pp. 117-121.

WHO, (2006). "Constitution of the World Health Organization" - Basic Documents, Fortyfifth edition, Supplement, October 2006.

WHO, (2014). Summary Results, Sensitivity Analyses, and Future Directions. Bulletin of the World Health Organization, WHO, 72 (3):495-508.

WHO, (2016). Over $90 \%$ of world breathing bad air-Health-Pulse. http://pulse.ng/health/world-healthorganization-over-90-of-world-breathing-bad-airid5535389.html?utm_medium=email\&utm_campaign=daily-2016-09-28\&utm_source=newsletter Accessed 27/09/2016.

Willis, K. G. and Garrod, D. (1999). Externalities from extraction of aggregates regulation by tax or land-use controls. Resources Policy, 25,pp 77-153.

Yablokov, A. (2013). A Review and Critical Analysis of the "Effective Dose of Radiation" Concept. Journal of Health \& Pollution Vol. 3, No. 5. 